\title{
Growth sensitivity in the epiphyseal growth plate, liver and muscle of SD rats is significantly enhanced by treatment with a fermented soybean product (cheonggukjang) through stimulation of growth hormone secretion
}

\author{
IN SIK HWANG ${ }^{1}$, JI EUN KIM ${ }^{1}$, YOUNG JU LEE ${ }^{1}$, MUN HWA KWAK ${ }^{1}$, HONG GU LEE ${ }^{2}$, \\ HYE SUNG KIM ${ }^{3}$, HEE SEOB LEE ${ }^{4}$ and DAE YOUN HWANG ${ }^{1}$
}

\begin{abstract}
${ }^{1}$ Department of Biomaterials Science, College of Natural Resources and Life Science/Life and Industry Convergence Research Institute, Pusan National University, Miryang-si 627-706; ${ }^{2}$ Department of Animal Science and Technology, College of Animal Bioscience and Technology, Konkuk University, Seoul 133-702; ${ }^{3}$ Department of Nanomaterials Engineering, College of Nanoscience and Nanotechnology, Pusan National University, Miryang-si 627-706; ${ }^{4}$ Department of Food Science and Nutrition, College of Human Ecology, Pusan National University, Busan 609-735, Republic of Korea
\end{abstract}

Received March 21, 2013; Accepted October 16, 2013

DOI: $10.3892 / \mathrm{mmr} .2013 .1757$

\begin{abstract}
Cheonggukjang (CKJ), a fermented soybean product, has been reported to have beneficial effects on various chronic diseases, including cardiovascular disease, cancer and immune diseases. To investigate whether CKJ induces growth sensitivity in mammals, alterations of key parameters related to their growth were analyzed. Sprague-Dawley (SD) rats were treated with a high concentration of CKJ (H-CKJ) or a low concentration of CKJ (L-CKJ) for 10 days, and compared with vehicle-treated rats. The $\mathrm{CKJ}$ contained a high concentration of total flavonoids, phenolic compounds, daidzein and genistein, compared with the non-fermented soybean product. Body weight was higher in the $\mathrm{H}-\mathrm{CKJ}$-treated group compared with that in the vehicle- and L-CKJ-treated groups, whereas the weights of three organs (the brain, liver and kidney) were higher in the L-CKJ-treated group compared with the remaining two groups. However, no significant differences in femur length and weight were detected between the CKJand vehicle-treated groups. The thickness of the epiphyseal growth plate in proximal femoral epiphysis was broadest in the H-CKJ-treated group compared with the vehicle- and L-CKJ-treated groups. Furthermore, the level of growth hormone $(\mathrm{GH})$ was highest in the serum of the L-CKJ-treated group, although that of the H-CKJ-treated group was lower compared with that in the L-CKJ group. Moreover, the expres-
\end{abstract}

Correspondence to: Professor Dae Youn Hwang, Department of Biomaterial Science, College of Natural Resources and Life Science, Pusan National University, 50 Cheonghak-ri, Samnangjin-eup Miryang-si, Gyeongsangnam-do 627-706, Republic of Korea E-mail: dyhwang@pusan.ac.kr

Key words: bone growth, cheonggukjang, growth hormone, growth hormone receptor, growth plate sion levels of the $\mathrm{GH}$ receptor increased in the liver tissue, but not in the muscle tissue, of the L-CKJ- and H-CKJ-treated groups. In the downstream signaling pathway of the $\mathrm{GH}$ receptor, the phosphorylation levels of Akt and Erk were differentially regulated between the liver and muscle. These results suggest that $\mathrm{CKJ}$ extract may enhance the sensitivity of the femur, liver and muscle epiphyseal growth plate in SD rats, through the upregulation of GH secretion.

\section{Introduction}

Soybean is widely used to produce various fermented products, including cheonggukjang (CKJ), doenjang and gochujang in Korea. Of these products, $\mathrm{CKJ}$ is predominantly produced by fermentation with Bacillus subtilis for a short time. It contains numerous enzymes, microorganisms and bioactive compounds that are absent from unfermented soybean $(1,2)$. In particular, flavonoid glycosides are converted into aglycones by hydrolysis, and a number of proteins are degraded into small peptides and amino acids during fermentation $(3,4)$.

CKJ exhibits diverse biological and pharmacological activities, including anti-obesity, antidiabetic and anti-inflammatory effects on human chronic diseases. In a study involving human subjects, CKJ supplementation was shown to significantly decrease visceral fat mass and apolipoprotein B/A1 levels (5). In another study, C57BL/6J mice exhibiting diet-induced obesity showed improvements in body weight, epididymal fat accumulation, and serum total cholesterol and low-density lipoprotein cholesterol levels, following CKJ treatment for 9 weeks (6). Furthermore, supplementation of CKJ has been shown to significantly reduce blood glucose and glycoslylated hemoglobin levels, as well as improve insulin tolerance in $\mathrm{C} 57 \mathrm{BL} / \mathrm{Ksj}-d b / d b$ mice (a type II diabetic animal model) $(7,8)$. In addition, when the anti-inflammatory activity of CKJ was investigated in the rat model of type I hypersensitivity and arachidonic acid-induced ear edema, CKJ treatment was 
demonstrated to decrease passive cutaneous anaphylaxis (9). Moreover, ethanol extracts of CKJ were shown to significantly increase the viability of cultured mice spleen and thymus cells, by suppressing apoptotic death (10). Although CKJ shows a variety of therapeutic activities in human disease, its effect on the sensitivity of body growth has not yet been investigated.

Therefore, in the present study, we investigated whether oral administration of CKJ significantly improves body growth via growth hormone $(\mathrm{GH})$ secretion in young Sprague Dawley (SD) rats. The data presented provide strong evidence that CKJ is a potential candidate for the stimulation or enhancement of animal growth from infancy to adulthood.

\section{Materials and methods}

Preparation of CKJ sample. CKJ was manufactured using the Pungwon soybean strain that was kindly supplied by the National Institute of Crop Science in Miryang, Korea. The B. subtilis was supplied by the Applied and Environmental Microbiology Laboratory at Pusan National University (Miryang, Korea). To prepare the CKJ, the soybeans (100 g) were first washed, then soaked for $12 \mathrm{~h}$ with three volumes of tap water at room temperature. The soybeans were then treated with hot steam at $121^{\circ} \mathrm{C}$ for $30 \mathrm{~min}$, before being allowed to cool to $37^{\circ} \mathrm{C}$. Once cool, the steamed soybeans were inoculated with $5 \%$ (w/w) B. subtilis $\left(1 \times 10^{9}\right.$ cells $\left./ \mathrm{ml}\right)$, followed by fermentation at $37^{\circ} \mathrm{C}$ for $48 \mathrm{~h}$. Powder of fermented soybeans (CKJ) was then prepared by freeze-drying, homogenization and sifting. The final CKJ sample extract was stored at $-75^{\circ} \mathrm{C}$ prior to use.

Principle component analysis of CKJ. Freeze-dried CKJ powder (1 g) was subjected to extraction with $10 \mathrm{ml}$ of distilled water at $70^{\circ} \mathrm{C}$ for $2 \mathrm{~h}$. The sample was centrifuged (10 min, $102 \mathrm{x} \mathrm{g}$ ) and the supernatant was collected for analysis. The concentration of total phenolics in CKJ was determined according to the Folin-Ciocalteu method (11). The sample $(20 \mu \mathrm{l})$ was mixed with $100 \mu \mathrm{l}$ of $0.2 \mathrm{~N}$ FolinCiocalteu reagent (Merck KGaA, Darmstadt, Germany) for $5 \mathrm{~min}$, and then combined with $300 \mu \mathrm{l}$ of $20 \%$ sodium carbonate. Following incubation at room temperature for $2 \mathrm{~h}$, the absorbance of the reaction mixture was measured at $765 \mathrm{~nm}$. Gallic acid (Sigma-Aldrich, St. Louis, MO, USA) was used as a standard to produce the calibration curve. Total phenolic content was expressed as gallic acid equivalents (mg) per gram of CKJ powder. The level of total flavonoids in CKJ was determined according to the method of Meda et al (12). The sample (200 $\mu \mathrm{l})$ was added to test tubes containing $60 \mu \mathrm{l}$ of $5 \%$ potassium nitrite, $600 \mu \mathrm{l}$ of distilled water and $60 \mu \mathrm{l}$ of $10 \%$ aluminum chloride. Following incubation at $25^{\circ} \mathrm{C}$ for $5 \mathrm{~min}$, the absorbance of the reaction mixture was measured at $510 \mathrm{~nm}$. The total flavonoid content was determined using a standard curve, with quercetin as a standard, and was expressed as quercetin equivalents (mg) per gram of CKJ powder. Furthermore, the total protein content was determined by the Bradford method (13), using bovine serum albumin as a standard. Total sugar content was determined according to the method of Dubois et al (14) with the modifications indicated below. The samples $(0.5 \mathrm{ml})$ and the $5 \%(\mathrm{w} / \mathrm{v})$ phenol solution $(0.5 \mathrm{ml})$ were added to screw cap tubes, which were capped and vortex-stirred. Then $2.5 \mathrm{ml}$ of concentrated sulfuric acid was added and mixed by vortexing. After incubation for $20 \mathrm{~min}$ at room temperature, the absorbance was measured at $490 \mathrm{~nm}$ using a spectrophotometer (BioSpec-mini; Shimadzu Corp., Kyoto, Japan).

High-performance liquid chromatography (HPLC) analysis of daidzein and genistein concentration. The concentration of daidzein and genistein in CKJ was analyzed, using a previously described method (15). Standard samples of $98 \%$ daidzein and $99 \%$ genistein were purchased from Sigma-Aldrich. The aqueous extracts of CKJ were mixed with $50 \%$ methanol and then this mixture was filtered with a $0.2-\mu \mathrm{m}$ membrane filter (Wayers Co., Milford, MA, USA), before HPLC injection. The daidzein and genistein concentration was analyzed by the iLC 3000 HPLC system (Interface Engineering, Seoul, Korea) equipped with a Corona ${ }^{\circledR} \mathrm{CAD}^{\circledR}$ Detector (ESA Biosciences, Inc., Chelmsford, MA, USA). The chromatographic separation was performed on a CAPCELL PAK MG C18 (4.6x250 mm; particle size, $5 \mu \mathrm{m}$; Shiseido Co. Ltd., Tokyo, Japan). The mobile phase consisted of solvent A (deionized water) and solvent B (acetonitrile), using the gradient elution program: 0-25 min, $30-90 \%$ of solvent B and $25-40 \mathrm{~min}, 90 \%$ of solvent B. A flow rate of $1.0 \mathrm{ml} / \mathrm{min}$ was used for the sample analysis. The nebulizer gas was compressed nitrogen. The gas flow rate and gas pressure were maintained at $1.53 \mathrm{l} / \mathrm{min}$ and $35 \pm 2 \mathrm{psi}$, respectively. The output signal of the detector was recorded using Clarity ${ }^{\mathrm{TM}}$ chromatography software (DataApex, Prague, Czech Republic).

Care and use of animals. Four-week-old female SD rats (SamTacho, Osan, Korea) were bred at the Pusan National University-Laboratory Animal Resources Center (Korea Food and Drug Administration accredited; registration no., 231). The SD rats received an ad libitum diet of standard irradiated chow (Purina Mills, Seoungnam, Korea). The rats were maintained in specific pathogen-free conditions under a strict 12-h light/dark cycle (lights on at 6:00 a.m. and off at 6:00 p.m.), at a temperature of $23 \pm 2{ }^{\circ} \mathrm{C}$, with $50 \pm 10 \%$ relative humidity, according to the Guide for Laboratory Animals (Institute for Laboratory Animal Research, Washington, DC, USA). Animal experiment protocols were carefully reviewed and approved in accordance with the ethical and scientific care procedures of the Pusan National University-Institutional Animal Care and Use Committee (approval no. PNU-2012-0006).

Experimental design and detection of body/organ weights. A total of 15 four-week-old female SD rats were divided randomly into three groups, with five rats per group. The first [low concentration of CKJ (L-CKJ)-treated] and second [high concentration of CKJ $(\mathrm{H}-\mathrm{CKJ})$-treated] groups of rats received 50 and $100 \mathrm{mg} / \mathrm{kg}$ body weight/day of CKJ extract diluted in water, respectively, via oral administration. The third group (vehicle-treated) received a daily administration of a comparable volume of water. The body weights of the rats were measured using an electronic balance (Mettler Toledo, Greifensee, Switzerland) at the indicated time points during the experimental period. At 10 days after the CKJ treatment, all animals were sacrificed using $\mathrm{CO}_{2}$ gas and the weights of five organs collected from SD rats were also measured using the same method as that used to detect the body weight. 
Table I. Content of key components in CKJ.

\begin{tabular}{lcc}
\hline Components & $\begin{array}{c}\text { Non-fermented } \\
\text { soybean } \\
(\mathrm{mg} / \mathrm{g})\end{array}$ & $\begin{array}{c}\text { Fermented soybean } \\
\text { (cheonggukjang) } \\
(\mathrm{mg} / \mathrm{g})\end{array}$ \\
\hline Protein & 489.060 & $565.030 \pm 12.141^{\mathrm{a}}$ \\
Total sugar & 5.141 & $5.252 \pm 0.721$ \\
Total flavonoid & 0.595 & $0.761 \pm 0.094^{\mathrm{a}}$ \\
Total phenolic & 8.927 & $9.861 \pm 0.885^{\mathrm{a}}$ \\
compound & & \\
\hline
\end{tabular}

CKJ, cheonggukjang. Data are expressed as the means $\pm \mathrm{SD}$. ${ }^{\mathrm{a}} \mathrm{P}<0.05$, compared with the non-fermented soybean.

Furthermore, bone and tissue samples were acquired and stored in Eppendorf tubes at $-70^{\circ} \mathrm{C}$ until assay.

Western blotting. Protein prepared from liver and muscle tissues of vehicle-, L-CKJ- and H-CKJ-treated rats were separated by $4-20 \%$ sodium dodecyl sulfate-polyacrylamide gel electrophoresis for $3 \mathrm{~h}$, following which, the resolved proteins were transferred to nitrocellulose membranes for $2 \mathrm{~h}$ at $40 \mathrm{~V}$. Each membrane was incubated separately with the following primary antibodies overnight at $4^{\circ} \mathrm{C}$ : Anti-GH receptor (ab78426; Abcam, Cambridge, UK), anti-Erk (sc-94; Santa Cruz Biotechnology, Inc., Santa Cruz, CA, USA), anti-pErk (sc-7383; Santa Cruz Biotechnology, Inc.), anti-Akt (\#9272; Cell Signaling Technology, Inc., Danvers, MA, USA), anti-pAkt (\#4058; Cell Signaling Technology, Inc.), and anti-actin (A5316; Sigma-Aldrich). The membranes were then washed with washing buffer $(137 \mathrm{mM} \mathrm{NaCl}$, $2.7 \mathrm{mM} \mathrm{KCl}, 10 \mathrm{mM} \mathrm{Na}_{2} \mathrm{HPO}_{4}, 2 \mathrm{mM} \mathrm{KH}_{2} \mathrm{PO}_{4}$ and $0.05 \%$ Tween 20) and incubated with horseradish peroxidase (HRP)-conjugated goat anti-rabbit IgG (Zymed Laboratories, Inc., South San Francisco, CA, USA) at a 1:1,000 dilution, at room temperature for $2 \mathrm{~h}$. Membrane blots were developed using a Chemiluminescence Reagent Plus kit (Pfizer, New York, NY, USA).

Histological analysis and observation by optical microscopy. Femur bones collected from the SD rats were fixed with $10 \%$ formalin, for at least two days at room temperature. The fixed femur bones were then demineralized for four days in $15 \%$ formic acid-prepared deionized water, embedded in paraffin wax and sectioned into $4-\mu \mathrm{m}$ slices. Bone sections were subsequently stained with hematoxylin and eosin (Sigma-Aldrich) and observed by optical microscopy. The thickness of the epiphyseal growth plate was measured at three points using the Leica Application Suite [Leica Microsystems (Schweiz) AG, Heerbrugg, Switzerland].

Quantification of GH by enzyme-linked immunosorbent assay (ELISA). The concentration of GH in sera collected from vehicle- and CKJ-treated rats was determined by following the ultra-sensitive assay procedure, using reagents in the Growth Hormone Rat ELISA kit (KRC5311; Invitrogen Life Technologies, Carlsbad, CA, USA). The sera and standards
A

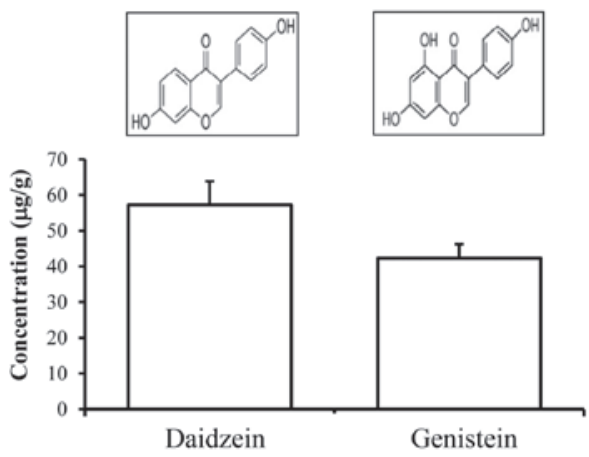

B

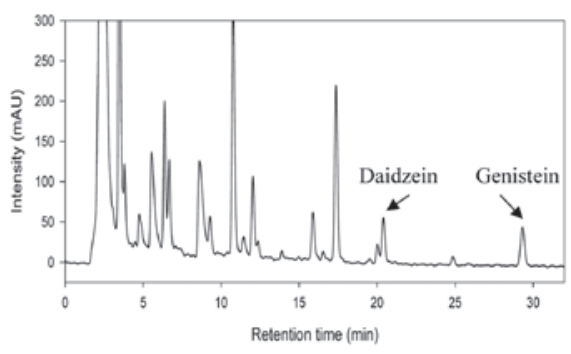

Figure 1. Concentration of daidzein and genistein. (A) Concentration and (B) chromatogram of daidzein and genistein from cheonggukjang.

were incubated in antibody-coated plates for $2 \mathrm{~h}$ at room temperature on a plate shaker at 51-61 x g. The wells were then washed six times using a PV100 automatic plate washer (Hoefer Inc., Holliston, MA, USA). HRP conjugates were subsequently added to all wells, followed by incubation for $30 \mathrm{~min}$ at room temperature on the shaker. The reaction was terminated by the addition of $50 \mu \mathrm{l}$ of stop solution. Color alterations in the wells were read using a VMax ${ }^{\circledR}$ microplate reader (Molecular Devices, Sunnyvale, CA, USA) at $450 \mathrm{~nm}$.

Statistical analysis. The significance of differences between the vehicle- and CKJ-treated groups in SD rats was analyzed using one-way ANOVA (SPSS for Windows, Release 10.10, Standard Version; SPSS Inc., Chicago, IL, USA). P $<0.05$ was considered to indicate a statistically significant difference. Values are presented as the mean \pm standard deviation.

\section{Results}

Concentration of key components in CKJ. To identify changes in the functional components of $\mathrm{CKJ}$, the concentration of several important components, including proteins, total flavonoids and total phenolic compounds, were measured using a number of traditional methods. The levels of these three aforementioned components significantly increased following fermentation of the soybean (Table I). However, no significant alteration in the total sugar concentration was detected. In addition, the levels of two key components that were correlated with the putative beneficial effects for animal growth, were measured by HPLC analysis. The concentration of daidzein was detected as $57.19 \mu \mathrm{g} / \mathrm{g}$, while the concentration of genistein was detected as $42.31 \mu \mathrm{g} / \mathrm{g}$ (Fig. 1). Therefore, the aforementioned results indicate that the CKJ used in this study contained high concentrations of protein, total flavonoids, total phenolic compounds, daidzein and genistein. 
A

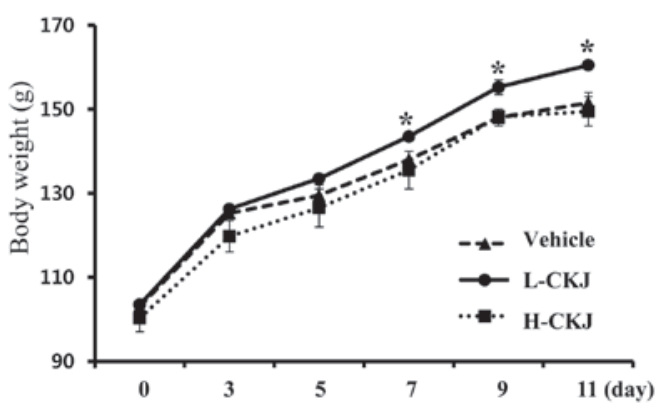

B
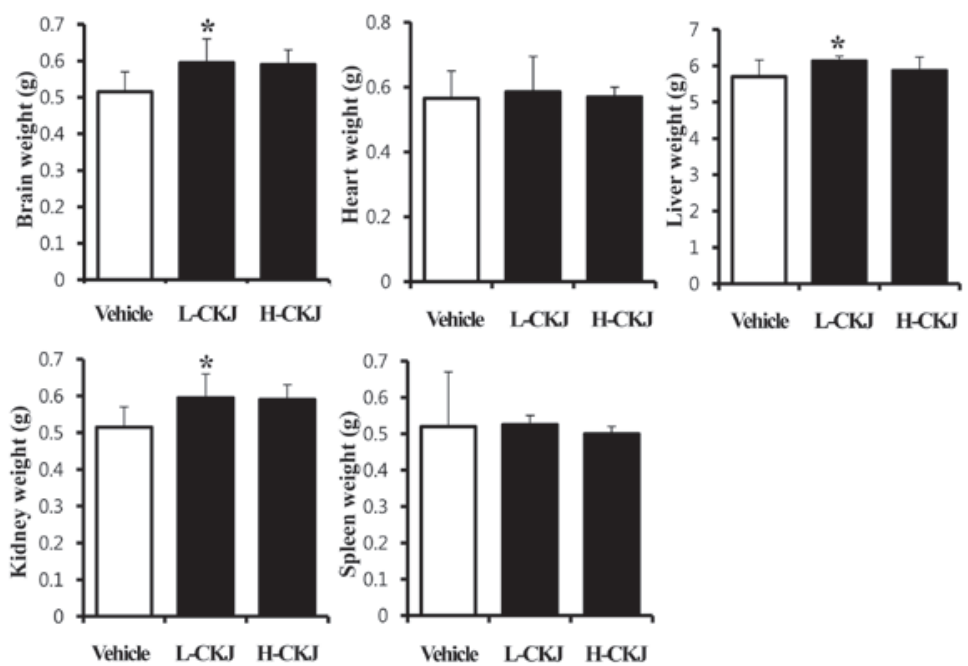

Figure 2. Effects of CKJ on body weight of Sprague-Dawley (SD) rats. (A) Following the administration of two concentrations of CKJ to SD rats, body weight was measured using an electronic balance daily for 11 days. (B) After final administration, five organs were collected from SD rats and weights were measured using an electric balance, as described in Materials and methods. Data are reported as the means \pm SD of three replicates. ${ }^{*}<0.05$, compared with the vehicletreated group. L-CKJ, low concentration of cheonggukjang; H-CKJ, high concentration of cheonggukjang.

Effect of CKJ on total body and organ weights. In order to determine the short-term effects of CKJ on animal growth, alterations of total body and organ weight in young SD rats were detected following CKJ administration for 10 days. The body weights of L-CKJ-treated rats were significantly higher compared with those of vehicle-treated SD rats from days seven to 11 . However, in the H-CKJ-treated group, an increase in body weight was detected only on day three, and its level returned to that of the vehicle-treated group from day five (Fig. 2A).

Furthermore, of the five important organs, the weights of the brain, liver and kidney significantly increased in the L-CKJ-treated group compared with those in the vehicle-treated group. However, heart and spleen weights were maintained at constant levels in the L-CKJ- and $\mathrm{H}-\mathrm{CKJ}$-treated groups (Fig. 2B). These results suggest that the L-CKJ induced significant increases in total body and organ weights in young SD rats.

Effect of CKJ on the weight and length of the femur, and thickness of the epiphyseal growth plate. To investigate the effect of short-term CKJ treatment on skeletal growth, femur weight and length were measured in young SD rats treated with two different concentrations of CKJ. The femur is the most proximal bone of the leg in tetrapod vertebrates capable of walking or jumping (16). Therefore, we selected the femur as a skeletal growth indicator and investigated its characteristics in relation to the growth of young rats. Notably, significant alterations in the femur weight and length were not detected in $\mathrm{SD}$ rats treated with L-CKJ or H-CKJ for 10 days (Fig. 3A). However, a marked difference was observed in the epiphyseal growth plate of the distal femur. In the H-CKJ-treated group, the thickness of the epiphyseal growth plate significantly increased compared with that of the vehicle-treated group. The number of cells in the proliferation and hypertrophy zone of the growth plate significantly increased in this group. Furthermore, the thickness of the epiphyseal growth plate in the L-CKJ-treated group was marginally enhanced compared with that of the H-CKJ-treated group (Fig. 3B). The aforementioned results suggest that short-term CKJ treatment stimulated the growth of epiphyseal plate in young SD rats, although there was no direct effect on femur weight and length.

Effect of CKJ on GH secretion from the pituitary gland. To investigate the effects of short-term CKJ treatment on GH secretion ability, alteration of the $\mathrm{GH}$ concentration was examined in young SD male rats following CKJ treatment for 10 days. The $\mathrm{GH}$ concentration in the blood serum significantly increased in the L-CKJ-treated group compared with that of the vehicletreated group. However, the H-CKJ-treated group showed a $37 \%$ lower GH level compared with that of the L-CKJ-treated rats, although its level remained markedly higher compared with that of the vehicle-treated group (Fig. 4A). These results show that the L-CKJ treatment induced GH secretion from the pituitary gland. 
A

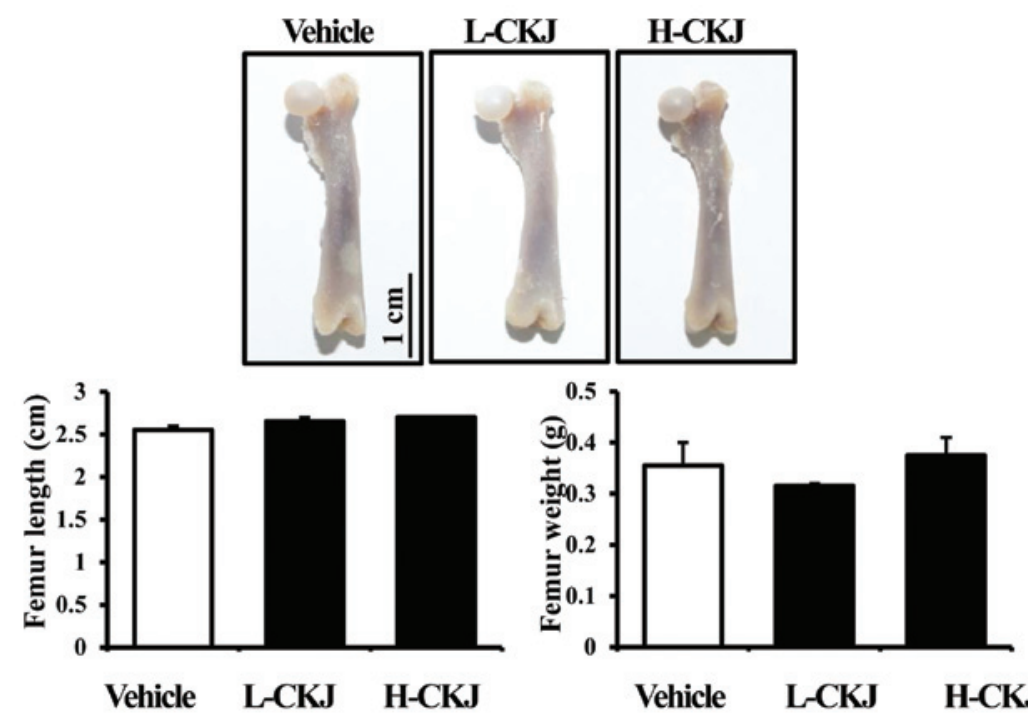

B
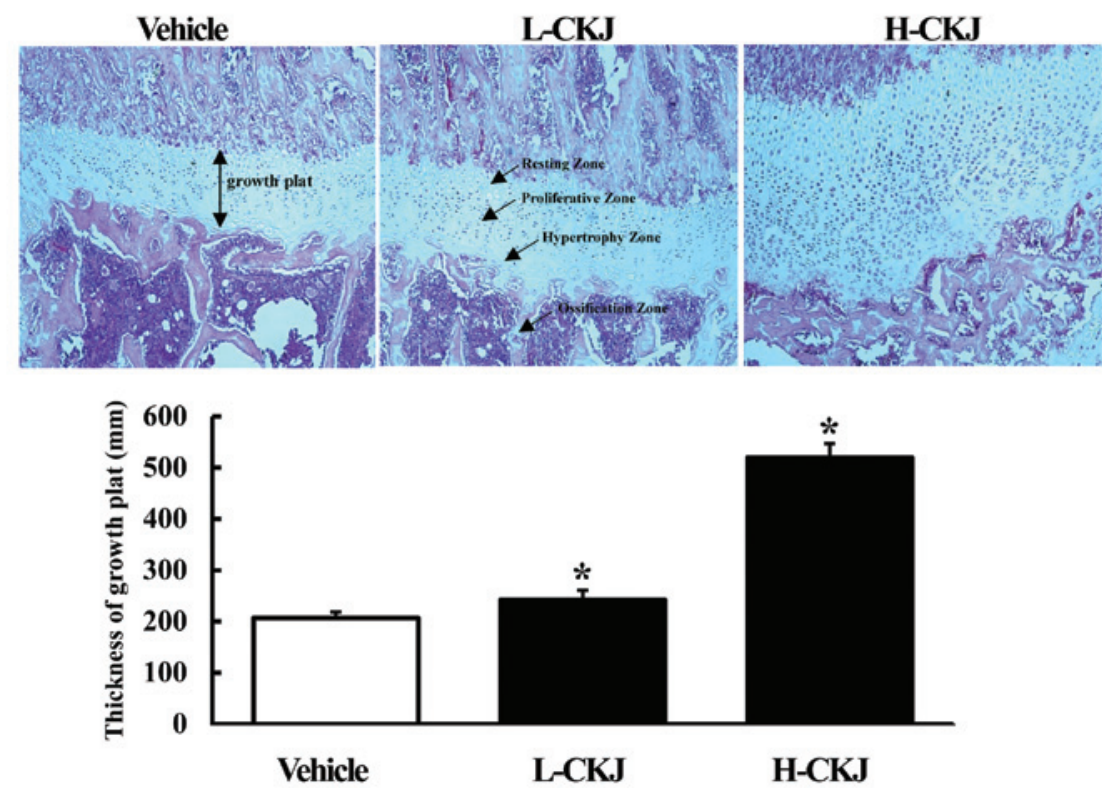

Figure 3. Morphological and histological alteration of femur bone growth in Sprague-Dawley rats. (A) Femur length was measured from the fovea capitis to medial condyle after careful trimming. (B) Thickness of epiphyseal growth plate was measured on the femur section stained with hematoxylin and eosin. Histological morphology was viewed at a magnification of $\mathrm{x} 20$. Data are presented as the means \pm SD of three replicates. " $\mathrm{P}<0.05$, compared with the vehicletreated group. L-CKJ, low concentration of cheonggukjang; H-CKJ, high concentration of cheonggukjang.

Effect of CKJ on GH sensitivity in the liver and muscle. To test whether the CKJ treatment has an effect on GH sensitivity in two target organs, the expression levels of the GH receptor and downstream proteins were analyzed in the liver and muscle of SD rats. The liver tissue showed a dose-dependent response to the CKJ treatment in terms of $\mathrm{GH}$ receptor expression, although the H-CKJ-treated group showed significantly higher $\mathrm{GH}$ receptor expression compared to the L-CKJ-treated group. However, the muscle tissue did not show any response to the CKJ treatment (Fig. 4B). Of the downstream signaling proteins in the GH receptor pathway, Akt and Erk were selected as key target proteins for the investigation of GH sensitivity. In the liver, the phosphorylation level of Akt significantly decreased in both the L-CKJ- and H-CKJ-treated groups compared with that of the vehicle-treated group. However, in the muscle, its level was lower only in the L-CKJ-treated group and there was no change in Akt phosphorylation in the H-CKJ-treated group.
Furthermore, the expression levels of pAkt and Akt simultaneously decreased in a CKJ concentration-dependent manner. The phosphorylation pattern of Erk differed from that of Akt. In the liver tissue, the phosphorylation level of Erk marginally increased in the L-CKJ-treated group, whereas it slightly decreased in the H-CKJ-treated group. In the muscle tissue, the phosphorylation level of Erk was dependent on the CKJ concentration (Fig. 5). These results indicate that the CKJ treatment differentially regulated the response to $\mathrm{GH}$ in liver and muscle.

\section{Discussion}

Fermented soybean includes different types of isoflavones, such as daidzein, genistein, enistein and glycetin. Their functions are closely associated with lowering the risk of breast and prostate cancer, the risk of cardiovascular disease and improving bone health (1). Generally, the concentration of 
$\mathbf{A}_{\mathbf{A}}$

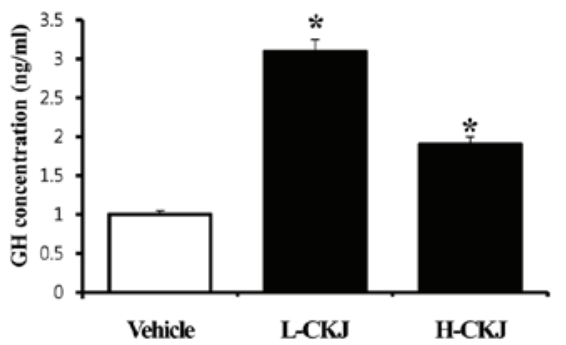

B
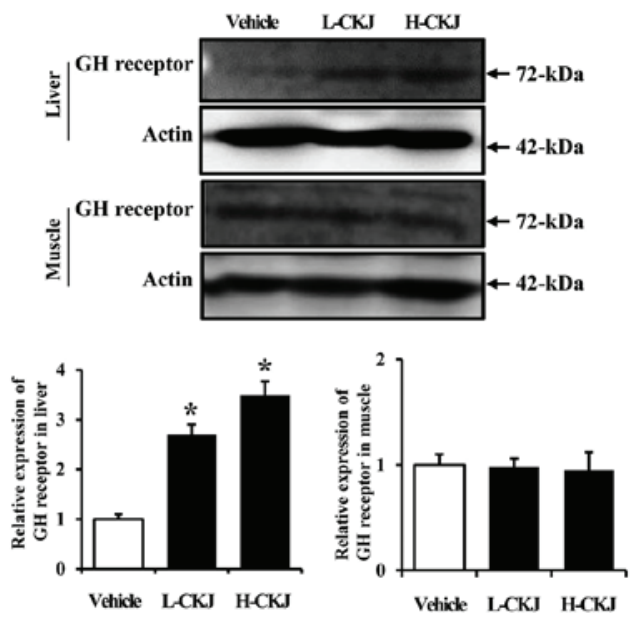

Figure 4. Alterations of $\mathrm{GH}$ concentration and $\mathrm{GH}$ receptor expression. (A) After final CKJ administration, blood sera were collected from each group of Sprague-Dawley rats. GH concentration was detected using an ELISA kit with $0.5 \mathrm{ng} / \mathrm{ml}$ of sensitivity. (B) $\mathrm{GH}$ receptor level was analyzed in two target organs, the liver and muscle, as described in Materials and methods. Data are presented as the means $\pm \mathrm{SD}$ of three replicates. ${ }^{*} \mathrm{P}<0.05$, compared with the vehicle-treated group. GH, growth hormone; L-CKJ, low concentration of cheonggukjang; $\mathrm{H}-\mathrm{CKJ}$, high concentration of cheonggukjang.

daidzein and genistein, which was analyzed in this study, was found to be significantly increased in fermented soybean (data not shown). In particular, the concentration of the two isoflavones in the $60 \%$ ethanol extract of the fermented soybean was $\sim 10$-fold greater than that from the non-fermented soybean (15). However, in a study using $80 \%$ ethanol extracts of fermented soybean, the concentration of daidzein was markedly increased compared with that of the non-fermented soybean, yet genistein was undetected in the two forms of the soybean (10). In the present study, using aqueous extracts of the CKJ, the results were in agreement with the aforementioned study, although the rate of increase varied. Therefore, we suggest that the high concentration of daidzein and genistein may be a key contributory factor in the bone growth of CKJ-treated SD rats.

The synthesis and secretion of GH in somatotroph cells of the anterior pituitary gland may be induced by several natural products $(17,18)$. For instance, administration of yeast extract for four weeks was shown to increase the body weight and GH secretion of young SD male rats (19). The bioassay-guided fraction of $\mathrm{MeOH}$ extract from the fenugreek (Trigonella foenum-graecum L.) seed stimulates the release of
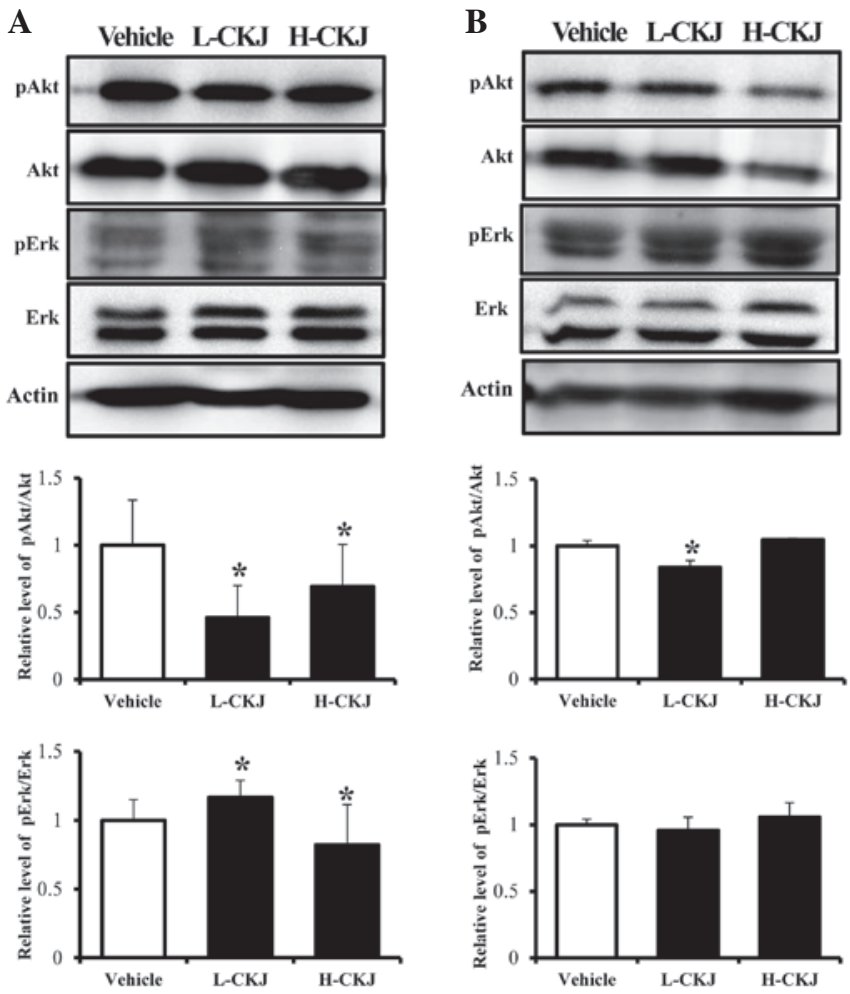

Figure 5. Effects of cheonggukjang (CKJ) administration on growth hormone $(\mathrm{GH})$ receptor downstream pathway proteins in (A) the liver and (B) the muscle using western blotting. Total cell lysates were prepared from tissues of vehicle-, L-CKJ-, and H-CKJ-treated groups, as described in Materials and methods. Fifty micrograms of protein per sample was immunoblotted using specific antibodies for each protein. Data are reported as the means \pm SD of three replicates. ${ }^{*} \mathrm{P}<0.05$, compared with the vehicle-treated group. $\mathrm{L}-\mathrm{CKJ}$, low concentration of cheonggukjang; $\mathrm{H}-\mathrm{CKJ}$, high concentration of cheonggukjang group.

GH from rat pituitary cells. In particular, fenugreek saponin I and dioscin have been demonstrated to induce marked increases in GH levels, compared with other compounds (20). In the case of Glycyrrhizae radix, its $\mathrm{MeOH}$ extract and n-hexane fraction induce GH secretion by up to 1.89 - and 4.59 -fold, respectively, compared with the basal level (21). Recently, GH stimulation has received attention as a treatment for overcoming short stature $(20,21)$. In an effort to identify medicinal foods that have a beneficial effect on human growth, the effect of CKJ on GH secretion in SD rats was investigated. As shown in Fig. 4, the results suggest that the $\mathrm{CKJ}$ was able to stimulate $\mathrm{GH}$ release from the pituitary gland.

Furthermore, GH receptor exists in two forms: The full-length membrane-bound human receptor and the GH-binding protein. After GH binds to its receptor, dimerization of the GH receptor is followed by phosphorylation of JAK2 and the GH receptor in cells. The signal induced downstream of the GH-GH receptor is transferred into the nucleus, where transcription factors, including signal transducers and activators of transcription, regulate the expression of the $\mathrm{GH}$ and $\mathrm{GH}$ receptor (22). Moreover, the GH-GH receptor complex is known to activate the PI3K pathway via JAK2 phosphorylation of IRSs (23). In this downstream pathway, Akt/PKB are important in numerous cell processes, including proliferation, survival and metabolism (24). Following direct injection of $\mathrm{GH}$ into mice, it was observed that phosphorylation of Akt 
decreases slightly in the liver, whereas it increases in muscle tissue (23). The results of the present study using liver tissue are in agreement with previous results (23). However, the results of the current study using muscle differ in that Akt phosphorylation decreased or remained unchanged in the CKJ-treated groups.

In addition, $\mathrm{GH}$ has been demonstrated to control cell proliferation, differentiation and migration through the regulation of mitogen-activated protein kinases, which are activated by several mitogens and growth factors (25). A previous study demonstrated a lower level of Erk phosphorylation in the liver of rats following GH treatment (23). However, in the present study, the phosphorylation level of Erk significantly increased in the two organs. Therefore, these results differ from previous results, in which the phosphorylation level of Erk decreased in the liver and remained unchanged in the muscle of GH-treated mice (23). We therefore suggest that this difference may be attributable to the various compositions of CKJ.

Bone growth may be induced by several natural compounds and extracts. The Buguzhi extract applied to the collagen matrix has the effect of stimulating new bone formation in the parietal bone of New Zealand white rabbits (26). Fetal bone growth may be stimulated by maternal administration of Cissus quadrangularis petroleum ether extract during pregnancy (27). Additionally, SD male rats fed yeast extract exhibit increased tibial bone and femur bone growth (19). This study investigated the effects of fermented soybean extract on bone growth in SD rats. The results differed greatly from those of previous studies. The CKJ treatment did not induce an increase in femur weight or length, although thickness of the growth plate markedly increased. Such a significant difference in femur bone growth may be attributed to the dose and period of the CKJ administration, or the extract composition.

In conclusion, these results suggest that treatment with CKJ, containing enhanced flavonoid and phenolic compounds, for a short time period improves GH sensitivity in the epiphyseal growth plate, liver and muscle of SD rats through the upregulation of $\mathrm{GH}$ secretion.

\section{Acknowledgements}

This study was supported by grants to Dr Dae Youn Hwang from the Korea Institute of Planning Evaluation for Technology of Food, Agriculture, Forestry and Fisheries (111030-3).

\section{References}

1. Lee JJ, Lee DS and Kim HB: Fermentation patterns of chungkookjang and Kanjang by Bacillus licheniformis B1. Kor J Microbiol 35: 296-301, 1999.

2. Su CL, Wu CJ, Chen FN, Wang BJ, Shen SR and Won SJ: Supernatant of bacterial fermented soybean induces apoptosis of human hepatocellular carcinoma Hep 3B cells via activation of caspase 8 and mitochondria. Food Chem Toxicol 45: 303-314, 2007.

3. Nakajima N, Nozaki N, Ishihara K, Ishikawa A and Tsuji H: Analysis of isoflavone content in tempeh, a fermented soybean and preparation of a new isoflavone-enriched tempeh. J Biosci Bioeng 100: 685-687, 2005.

4. Kwon DY, Jang JS, Lee JE, Kim YS, Shin DH and Park S: The isoflavonoid aglycone-rich fractions of Chungkukjang, fermented unsalted soybean, enhance insulin signaling and peroxisome proliferation-activated receptor-gamma activity in vitro. Biofactors 26: 245-258, 2006.
5. Baek HI, Kim SR, Yang JA, Kim MG, Chae SW and Cha YS: Effect of chungkookjang supplementation on obesity and atherosclerotic indices in overweight/obese subjects: a 12-week, randomized, double-blind, placebo-controlled clinical trial. J Med Food 14: 532-537, 2011.

6. Soh JR, Kwon DY and Cha YS: Hepatic gene expression profiles are altered by dietary unsalted Korean fermented soybean (chongkukjang) consumption in mice with diet-induced obesity. J Nutr Metab: March 9, 2011 (Epub ahead of print). doi: $10.1155 / 2011 / 260214$

7. Kim DJ, Jeong YJ, Kwon JH, Moon KD, Kim HJ, Jeon SM, Lee MK, Park YB and Choi MS: Beneficial effect of chungkukjang on regulating blood glucose and pancreatic $\beta$-cell functions in C75BL/Ksj-db/db mice. J Med Food 11: 215-223, 2008.

8. Kwon DY, Daily JW III, Kim HJ and Park S: Antidiabetic effects of fermented soybean products on type 2 diabetes. Nutr Res 30: $1-13,2010$.

9. Choi YH, Lim H, Heo MY, Kwon DY and Kim HP: Antiimflammatory activity of the ethanol extract of Chungkukjang, Korean fermented bean: 5-lipoxygenase inhibition. J Med Food 11: 539-543, 2008.

10. Kim HB, Lee HS, Kim SJ, Yoo HJ, Hwang JS, Chen G and Youn HJ: Ethanol extract of fermented soybean, Chungkookjang, inhibits the apoptosis of mouse spleen, and thymus cells. J Microbiol 45: 256-261, 2007.

11. Singleton VL, Orthofer R and Lamuela-Raventos RM: Analysis of total phenols and other oxidation substrates and antioxidants by means of Folin-Ciocalteu reagent. Methods Enzymol 299: $152-178,1999$.

12. Meda A, Lamien CE, Romito M, Millogo J and Nacoulma OG: Determination of the total phenolic, flavonoid and proline contents in Burkina Fasan honey, as well as their radical scavenging activity. Food Chem 91: 571-577, 2005.

13. Bradford MM: A rapid and sensitive method for the quantitation of microgram quantities of protein utilizing the principle of protein-dye binding. Anal Biochem 72: 248-254, 1976.

14. Dubois M, Gilles KA, Hamilton JK, Rebers PA and Smith F: Colorimetric method for determination of sugars and related substances. Anal Biochem 28: 350-356, 1956.

15. Zheng J, Jin Y and Row KH: Analysis of isoflavones from Korean and Chinese soybean and processed products by HPLC. J Kor Chem Soc 49: 349-354, 2005.

16. Nareliya R and Kumar V: Biomechanical analysis of human femur bone. Int J Eng Sci Tech 3: 3090-3094, 2011.

17. Daniels ME: Lilly's Humatrope experience. Nat Biotechnol 10: 792-812, 1992

18. Powers M: Performance-enhancing drugs. In: Principles of Pharmacology for Athletic Trainers. Houglum JE and Harrelson GL (eds). 2nd edition. SLACK Incorporated, Thorofare, NJ, pp331-332, 2005.

19. Kim JM, Kim SY, Jung EY, Bae SH and Suh HJ: Yeast hydrolysate induces longitudinal bone growth and growth hormone release in rats. Phytother Res 23: 731-736, 2009.

20. Shim SH, Lee EJ, Kim JS, Kang SS, Ha H, Lee HY, Kim C, Lee JH and Son KH: Rat growth-hormone release stimulators from fenugreek seeds. Chem Biodivers 5: 1753-1761, 2008.

21. Lee HY, Jung DY, Ha H, Kang SS, Kim JS and Kim C: Induction of growth hormone release by glycyrrhizae radix on rat. J Biochem Mol Biol 40: 979-985, 2007.

22. Postel-Vinay MC and Finidori J: Growth hormone receptor: structure and signal transduction. Eur J Endocrinol 133: 654-659, 1995.

23. Miquet JG, Muñoz MC, Giani JF, González L, Dominici FP, Bartke A, Turyn D and Sotelo AI: Ames dwarf (Prop1(df)/ Prop1(df)) mice display increased sensitivity of the major GH-signaling pathways in liver and skeletal muscle. Growth Horm IGF Res 20: 118-126, 2010.

24. Nicholson KM and Anderson NG: The protein kinase B/ Akt signalling pathway in human malignancy. Cell Signal 14: 381-395, 2002.

25. Nishimoto $\mathrm{S}$ and Nishida E: MAPK signalling: ERK5 versus ERK1/2. EMBO Rep 7: 782-786, 2006.

26. Wong RW and Rabie AB: Effect of Buguzhi (Psoralea corylifolia fruit) extract on bone formation. Phytother Res 24 (Suppl 2): S155-S160, 2010.

27. Potu BK, Rao MS, Kutty NG, Bhat KM, Chamallamudi MR and Nayak SR: Petroleum ether extract of Cissus quadrangularis (LINN) stimulates the growth of fetal bone during intra uterine developmental period: a morphometric analysis. Clinics (Sao Paulo) 63: 815-820, 2008. 